\title{
Arquitectura militar en la región de Jaina, Campeche, México. Falsedades en la historia defensiva colonial
}

\author{
Jorge Victoria Ojeda \\ Archivo General del Estado de Yucatán
}

El autor pasa revista a dos observaciones hechas sobre las fortificaciones en la región de Jaina que considera incorrectas, puesto que parten de la premisa de que estas construcciones datan del período colonial. Si bien un conocido mapa de las construcciones militares en la isla ha sido utilizado para fecharlas en el siglo XVIII, la información que lo acompaña es apócrifa. En la segunda parte, trata de la antigüedad de las fortificaciones del camino a Jaina, fechadas en los siglos XVII y XVIII; tras sopesar las distintas fechas posibles, concluye que las fortificaciones son, en realidad, posteriores a 1821. Esta corrección evitará errores en la evaluación de las estrategias de defensa coloniales en la península de Yucatán.

La defensa que España materializó en sus territorios del Caribe desde el siglo XVI al XVIII puede ser tomada como signo o elemento de poder en las tierras americanas, primero en relación a la empresa conquistadora y después como parte del circuito comercial, con lo que el "mediterráneo americano" quedó convertido en su "Mare Clausum". ${ }^{1}$ De tal forma, a raíz de las guerras desarrolladas a lo largo del siglo XVIII, la Corona jerarquizó lugares estratégicos en sus territorios de tierra firme y abrigos en la ruta de comercio, designándolos enclaves o "llaves" por su situación estratégica en lo político y militar, dotándolos de mejores sistemas de fortificación y, en lo posible, de mejores fuerzas físicas. ${ }^{2}$

Así, alternando con Cuba, denominada "llave del Nuevo Mundo y Antemural de las Indias", con Puerto Rico, "llave de las Antillas", y Veracruz, "llave del Virreinato de la Nueva España", por ejemplo, en la península de Yucatán existieron otras llaves, aunque de menor importancia, tales como la laguna de Términos, denominada "llave de la Capitanía General de Yucatán", el puerto de Campeche, "llave del comercio de la madera preciosa" y Bacalar, "llave del contrabando inglés". ${ }^{3}$

Aquellos puntos costeros no fueron los únicos con que, en materia defensiva, contó la península yucateca, sino que existieron otros menores,

1 Wood, Yolanda: "Proceso histórico-artístico del Caribe", en Arquitectura y Urbanismo, La Habana, 1987, pág. 6.

2 Zapatero, Juan: La guerra del Caribe en el siglo XVIII, Madrid, 1990, pág. 37.

3 Ibídem: págs. 39, 226-233. Para los casos de Yucatán, ver también: Ortiz Lanz, José Enrique: Arquitectura Militar en México, México, 1993, págs. 107-116, 132-156, 164-170. 
como Sisal, Nueva Málaga, Champotón y Lerma. Todas esas obras en su conjunto formaron parte del engranaje defensivo caribeño que la Corona procuró instalar para la salvaguarda de sus territorios de ultramar.

En las investigaciones referentes a las obras arquitectónicas realizadas durante los siglos de gobierno novohispano en la actual región mexicana - así como en las otras de América- es necesaria la consulta de diversos archivos en busca de manuscritos y planos que ayuden a los estudiosos en sus tareas. Sin embargo, la falta de la pertinente crítica a las fuentes puede llevar en algunas ocasiones a cometer errores que tergiversen la historia.

En el presente artículo se exponen dos casos de falsedades históricas, ambas en la misma región de Jaina, una por lo apócrifo de la información de un plano y la otra por la errada datación de unas obras de campaña. La falta de verificación de estos datos obligaba a ubicar la región mencionada dentro del plano peninsular de emplazamiento militar arquitectónico y a considerar el papel que jugó en la estrategia defensiva peninsular.

Hasta el siglo XIX varias partes del litoral yucateco permanecían deshabitadas o con escasa población por las características cenagosas de la costa. Algo semejante aconteció en la región de Jaina, al norte de la ciudad de Campeche, en el sureste mexicano, donde el manglar domina el paraje y sus bajas aguas son las únicas que propician una pequeña playa en toda esa parte de la costa. ${ }^{4}$ Sin embargo, un plano existente en el Museo Naval de Madrid acusa la existencia de una obra para la defensa de la isla de Jaina en el siglo XVIII. De igual manera, en el camino que conduce a esa isla existen numerosas barricadas o trincheras, provenientes, según algunos investigadores, de los siglos XVII o XVIII.

En el presente artículo se trata de corroborar la veracidad de la información señalada en el plano, así como la presentación de hipótesis en cuanto a la datación de las barricadas localizadas en el camino a la isla.

\section{Jaina: geografía e historia}

La isla de Jaina se localiza a 42 kilómetros al norte de la ciudad de Campeche, capital del estado mexicano del mismo nombres (fig. 1). Dicha

4 Ortiz Lanz, José Enrique: Piedras ante el mar. Las fortificaciones de Campeche, México, 1996, pág. 97, señala que durante el período colonial, la costa de barlovento de Campeche permaneció sin defensas ni vigías, pues se confiaba en las dificultades que representaban la poca profundidad de las aguas y la tupida vegetación para impedir una eventual aproximación. A la vez, se reconocía que Jaina era el único punto que pudiese servir como refugio en toda esa extensión.

5 Andrews, Anthony: "Reconocimiento arqueológico de la costa norte del Estado de Campeche”, Boletín ECAUADY, n. ${ }^{\circ}$ 19, Mérida, 1977, pág. 68. 


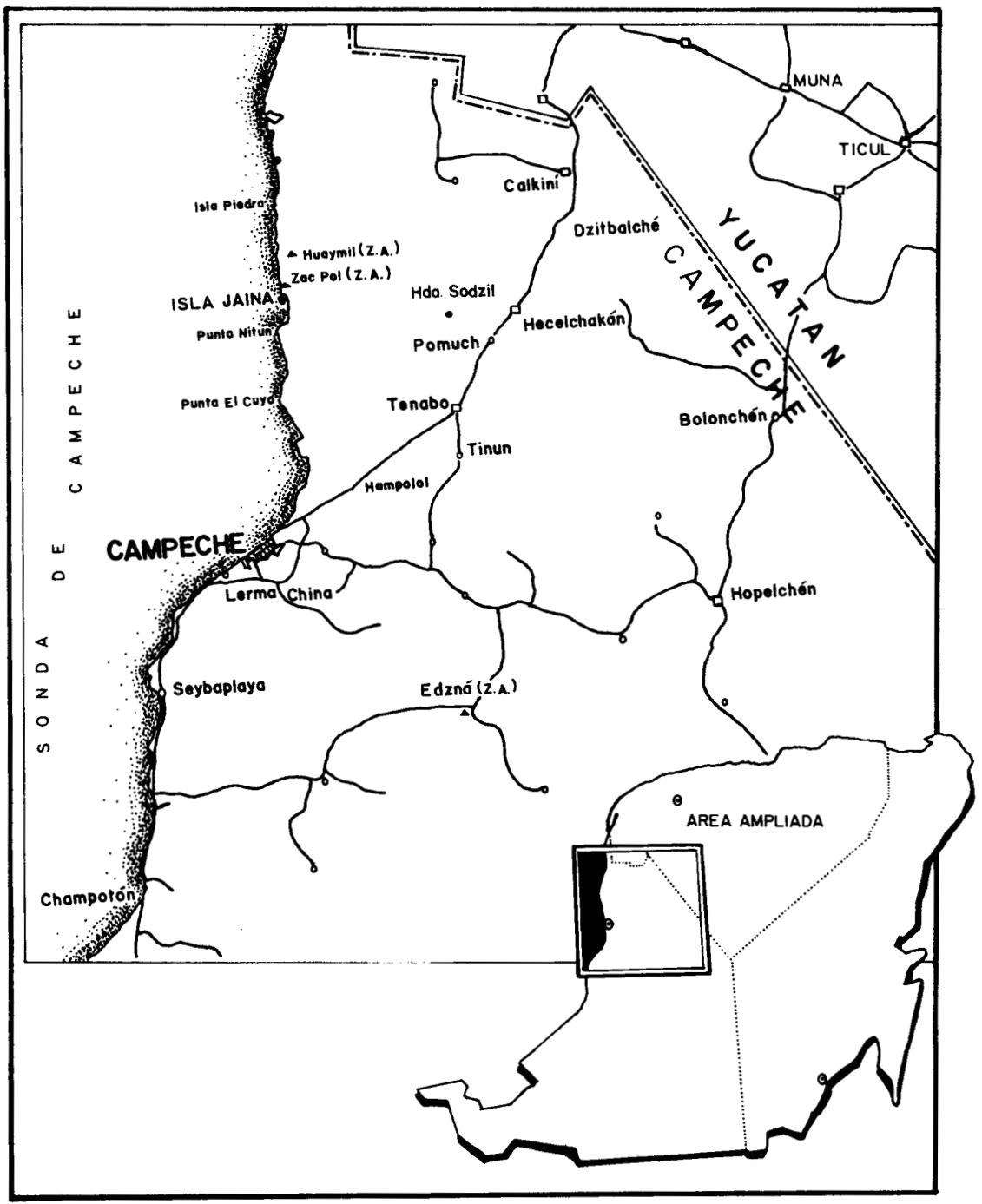

Fig. 1.-Localización de la isla de Jaina, Campeche 
isla presenta forma un tanto oval, con dimensiones de 1.000 metros de largo por 750 en su parte más ancha. Su superficie se caracteriza por la existencia de montículos prehispánicos, lomas y pequeños bordos de caracoles, concha y arena acumulados por las mareas ${ }^{6}$ (fig. 2).

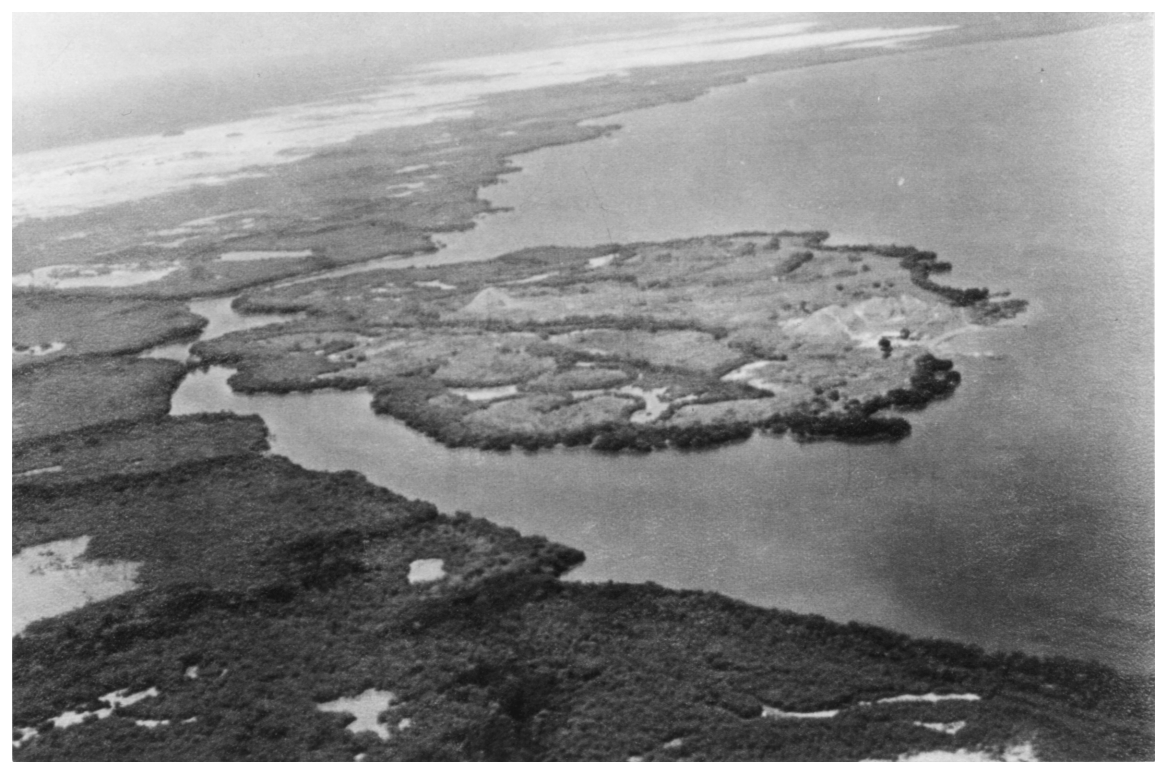

Fig. 2.- Vista aérea de la isla de Jaina. (Tomado de Piña Chan, 1968)

En el aspecto concerniente a la etapa prehispánica, los montículos y lomas de Jaina corresponden a un centro ceremonial y a zonas habitacionales, cuyo desarrollo puede datarse, de acuerdo a estudios cerámicos, entre el año 300 y el 1000 d.C. El centro del sitio maya se halla enclavado casi en la parte media de la isla, corriendo diagonalmente de NO a SE; quedando prácticamente limitado hacia el norte por un estrecho canal llamado Zacpool, mientras que hacia el SE se encuentra bordeado de árboles, yerbas y manglares. ${ }^{7}$

6 Piña Chan, Román: Jaina, México, 1968, pág. 27.

7 Ibídem, págs. 27, 63. 
La elevación que presenta el terreno sobre el nivel del mar en comparación con lo bajo de la costa es indicio de que la isla fue construida en su mayoría artificialmente, lo que se corrobora por la constitución de su suelo. ${ }^{8}$

En dirección a la parte central de Jaina corre un angosto canal, ya antes mencionado, por donde desaguan hacia el mar las aguas de las lluvias estacionales, aunque en la actualidad está muy azolvado. Ese canal fue llamado por el viajero e investigador Desiré Charney "río Zacpool", y posteriormente por Hubert Bancroft "río de Jaina".

La zona costera que queda frente a la isla es una franja caliza cubierta de manglares, pantanos salinos y bajos de marea, en donde la escasa tierra vegetal se ha convertido en lodo. A dos kilómetros tierra adentro este panorama se convierte en un denso monte, conformado por un suelo de tierra $\operatorname{roja}^{10}$ (fig. 3).

El mar es sumamente bajo en varios kilómetros frente a Jaina y las mareas extremosas, especialmente en los meses de noviembre a febrero, por lo que el agua cubre todas las partes bajas de la isla y penetra hasta el interior de la costa, o se retira mar adentro, a veces hasta una distancia de 500 metros, dejando al descubierto suelo fangoso y bancos de arena que la circundan. ${ }^{11}$

En 1766, el ingeniero Juan de Dios González apuntaba que las características de la región hacían impracticable el desembarco enemigo para invadir la provincia, aunque señalaba que los caminos que se estaban abriendo por algunas personas para sacar maderas pudiesen a la vez utilizarse como puertas y facilitar la penetración foránea. ${ }^{12}$

En 1843 se tienen las primeras noticias de la isla, al publicar B.M. Norman las impresiones de su viaje a Yucatán y Campeche, apuntando que a tres leguas hacia el norte de la ciudad de Campeche existía una pequeña península llamada Jaina. Asimismo y haciendo uso de las notas de Norman, en 1883 Bancroft señalaba que en la desembocadura del "río de Jaina" existía un montículo con cerámica y puntas de lanza en su superficie. ${ }^{13}$

8 Ibídem.

9 Ibídem, pág. 27.

10 Ibídem.

11 Ibídem, pág. 23.

12 Reconocimiento y estado de la Provincia de Yucatán, por el ingeniero Juan de Dios González, en Campeche a 18 de febrero de 1766. Servicio Histórico Militar (en adelante, SHM), Yucatán 5-3-9-9.

13 Piña Chan: Jaina, págs. 7-8. 


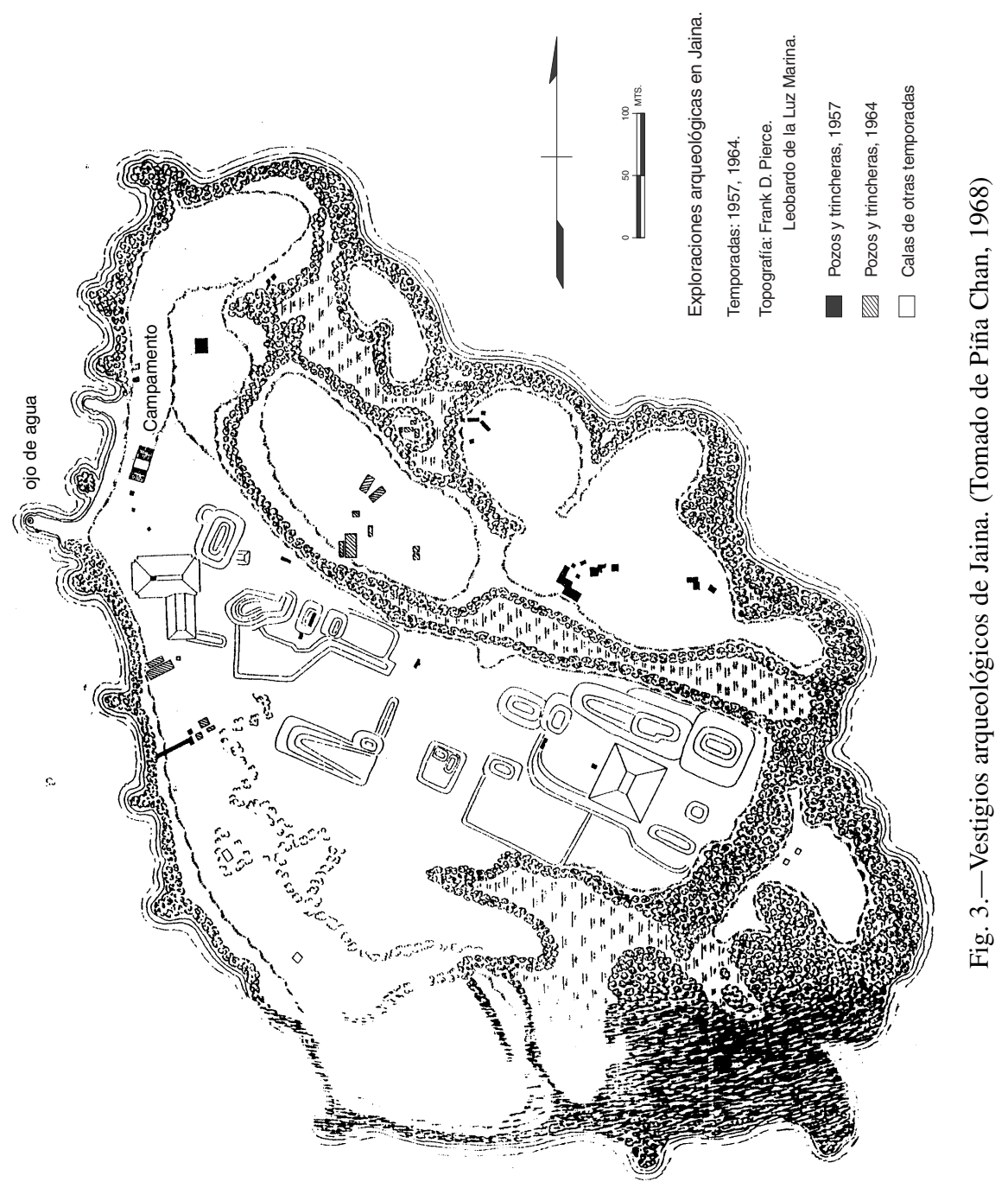


En 1886, Desiré Charney, en las memorias sobre su viaje y exploración arqueológica en Jaina, apuntaba lo siguiente:

"La isla... tiene tres kilómetros de largo por 800 metros de ancho poco más o menos y está separada de la tierra firme por un canal de 80 a 100 metros de latitud, que se seca cuando baja la marea, y en el cual desarrolla un arroyo llamado Sacpool, o sea cabeza blanca, porque el agua corre sobre un lecho calcáreo blanco". ${ }^{14}$

En 1924, Sylvanus Morley y O. Rickertson realizaron una breve visita al sitio, con el fin de estudiar las estelas mayas allí localizadas. Posteriormente, las exploraciones arqueológicas han sido emprendidas por el Instituto Nacional de Antropología e Historia de México. Así, a partir de la década de los cuarenta se han llevado a cabo trabajos por parte de Pavón Abreu, Moedano, Fernández, Quintana Bello, Ruz Lhuiller, Piña Chan, Cook de Leonard, Sáenz, ${ }^{15}$ Benavides, etc.

Por lo que se refiere a las costas aledañas a la isla cabe señalar que en 1955 E.M. Shook realizó un reconocimiento costero desde Campeche hasta Sisal; en 1968 J.D. Eaton realizó otro reconocimiento de las costas oeste y norte de la península, y en 1976 y 1977 el arqueólogo A. Andrews realizó un reconocimiento de toda la costa norte de Campeche. ${ }^{16}$

\section{Arquitectura defensiva de Jaina o lo apócrifo de un plano}

Los vestigios e investigaciones arqueológicas desarrolladas en Jaina y costas cercanas sirven de premisa para tratar a continuación el primer punto de este artículo: la obra defensiva colonial de la isla.

Un plano anónimo, según Antochiw proveniente tal vez de la segunda mitad del siglo XVIII y conservado en el Museo Naval de Madrid, lleva por título "Puesto de Jayna, de las baterías de campaña construidas en aquel destino, playas continuas y desembocadura de su río con expresión de su sonda" ${ }^{17}$ (fig. 4). Al caso, y contradiciendo al texto inscrito en el documento gráfico, el antropólogo Antochiw señala que el plano muestra las obras militares construidas no en la isla, sino enfrente de la misma. ${ }^{18}$ En contraposición, el investigador Ortiz Lanz es de la opinión de la existencia de la obra

14 Charney, Desiré: Viaje a Yucatán a fines de 1886, México, 1978, págs. 46-47.

15 Andrews: "Reconocimiento arqueológico...", págs. 66-67.

16 Ibídem, págs. 64-77. nas 260-261.

17 Antochiw, Michel: Historia cartográfica de la Península de Yucatán, México, 1994, pági-

18 Ibídem, pag.261. 


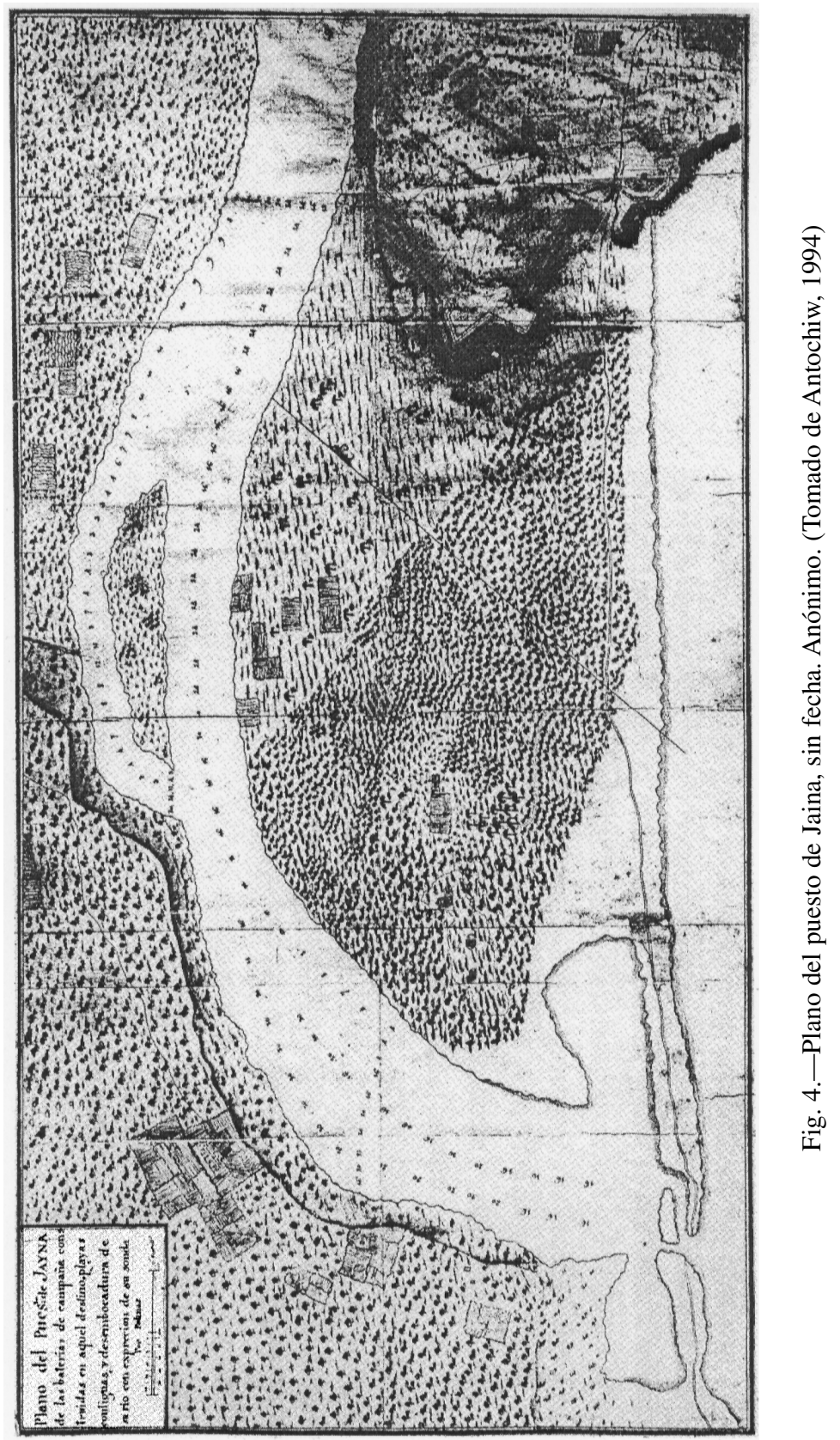


en Jaina, tal como se indica en el plano, señalando que debió haber sido construida con posterioridad a 1766, pues Juan de Dios González no la menciona en su relación de ese año. ${ }^{19}$

El interrogante que presenta este plano es la autenticidad de la información en él plasmada. El autor anónimo dibujó una batería capaz de 12 cañones, protegiendo la costa de la erosión con la acumulación de piedras que forman una especie de escollera. Atravesando el ancho de la isla se señala un parapeto o muro que presenta troneras en la parte triangular y rectangular, en una especie de baluarte que queda exactamente en medio de la isla (fig. 5). Según la distribución espacial de las obras, el posible ataque era de esperarse que ocurriera por el costado norte de Jaina. ${ }^{20}$ Cabe señalar que las obras indicadas en el plano anónimo no fueron reportadas en el reconocimiento de González en 1766, ${ }^{21}$ ni en el de Gabriel Muñoz del año siguiente. ${ }^{22}$ Lo mismo sucede en el plan de defensa para la plaza y provincia elaborado por Agustín Crame en $1779,{ }^{23}$ y en la descripción de la costa peninsular realizada por Miguel Molas en 1817. ${ }^{24} \mathrm{Y}$ aún más, en el plan de ataque e invasión a la provincia elaborado entre 1828 y 1829 por José Gora, para la reconquista de Yucatán por parte de España, no encontramos noticias de aquella defensa a pesar de que esa invasión se iniciaría con el desembarco de tropas por Jaina y Lerma. ${ }^{25}$ Gora únicamente señalaba para esos años la existencia de un cañón en la isla, localizado en lo alto de uno de los montículos prehispánicos, instalado por los habitantes de la población más cercana. ${ }^{26}$

El 15 de abril de 1845, el señor Cristóbal de Espínola, basándose en la cláusula cuarta del artículo primero de la ley emitida diez días antes, referente a la adquisición de tierras vendibles o enajenables, intentó adquirir en propiedad el terreno que ocupaba el rancho de Luis Aguilar, sito entre

19 Ortiz Lanz: Piedras ante el mar..., pag.97.

20 Este autor opina que la defensa consistía en una serie de "albarradas continuas que se ajustaban a la topografía tan variable de la isla". Ibídem.

21 Reconocimiento y estado de la Provincia...

22 Descripción de la costa de Yucatán desde Cabo Catoche hasta la Laguna de Términos. Mérida. Año de 1767. SHM, Yucatán 5-3-9-19.

23 Plan de defensa de la Plaza y Provincia de Campeche, hecho de orden del rey por el brigadier de Infantería Don Agustín Crame, de acuerdo con el coronel Don Roberto Ribas, gobernador y capitán general interino de dicha Provincia. Campeche 20 de mayo de 1779. SHM, Yucatán 5-3-11-17.

24 Molas, Miguel: "Derrotero de la Península de Yucatán, de todas sus costas e islas, bajos, puertos y arrecifes, trabajado por la práctica, experiencia y cumplido conocimiento de Don Miguel Molas, en el año de 1817”, Registro Yucateco, tomo 1, Mérida, 1845, págs. 115-124.

25 Sosa Rodríguez, Enrique: Proyectos de invasión a Yucatán desde Cuba 1828-1829, Mérida, 1996, pág. 61.

26 Dificultades para la toma de Yucatán. La Habana, septiembre 9 de 1828. Archivo Nacional de Cuba, Asuntos Políticos, 33, 77. 

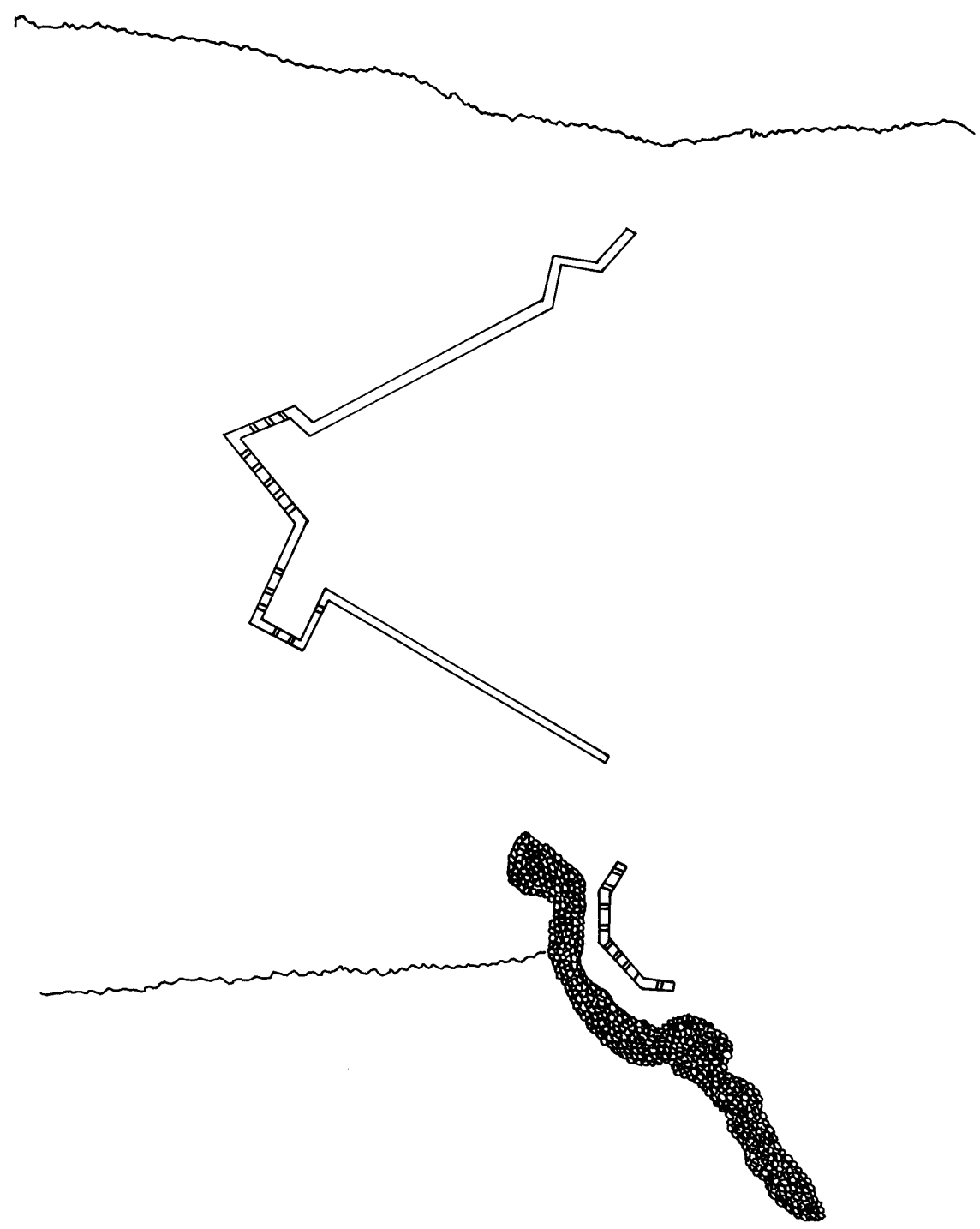

Fig. 5.-Detalle del plano del puerto de Jaina, sin fecha. Anónimo 
los dos que Espínola poseía en Jaina. En su solicitud, Espínola remitió a las autoridades un "exactísimo plano" que comprendía las "mil ciento noventa y tres y media varas de largo y setecientos treinta y siete y media varas de ancho, en donde se hallan cuatro ranchos de pesquería, pertenecientes a los ciudadanos Anastasio Carcaño, Ygnacio Medina, Luis Aguilar" y al propio Espínola, así como los montículos prehispánicos ${ }^{27}$ (fig. 6). El autor no indica la presencia de ninguna obra defensiva ni de la vigía instalada en 1833. De esta última se desconoce el tiempo que perduró, pero no es difícil que en lugar de la torre de la atalaya se haya aprovechado la altura de alguno de los cerros prehispánicos para realizar la vigilancia.

De tal forma, la defensa arquitectónica de Jaina no fue reportada por ninguno de los viajeros del siglo pasado, ni tampoco por los especialistas que han desarrollado trabajos arqueológicos en la presente centuria en aquel sitio prehispánico. Presuponemos que la costa de barlovento de Campeche quedó sin vigilancia durante la colonia hasta que se mandó instalar una vigía en aquella isla en $1808,{ }^{28}$ la cual permanecería poco tiempo, puesto que en 1833 de nueva cuenta se ordenó la existencia de una atalaya en la isla. En ese año se consideró que "habiendo tenido por conveniente esta comandancia general establecer una vigía en el punto de Jaina, le confirió este destino al sargento primero de la extinguida división de tiradores Gregorio Balverde, desde el 2 de febrero pasado, con sólo la paga de cinco pesos mensuales que disfruta por su empleo militar". Poco después el vigía estaba disconforme con su situación, pues a cinco meses de estar en el empleo no había recibido el salario estipulado. ${ }^{29}$

Los datos expuestos hasta ahora apuntan hacia lo apócrifo de la información mencionada en el plano de las obras militares de Jaina, lo que se complementa con los resultados del recorrido que en la isla y costa cercana realizó en mayo de 1996 el arqueólogo Antonio Benavides Castillo, del Instituto Nacional de Antropología e Historia de Campeche, con intenciones de verificar en el campo los datos del documento del siglo XVIII, así como lo opinado por Antochiw. El resultado fue negativo, por lo cual

27 Archivo General del Estado de Yucatán (en adelante, AGEY), Poder Ejecutivo, Gobernación, Secretaría General de Gobierno, Jefatura Política, 159, Campeche a 15 de abril de 1845. El 12 de junio del mismo año se señalaba que los terrenos que Espínola apuntaba como baldíos pertenecían a la comunidad de Pomuch, por lo cual se declaraba sin lugar su petición.

28 1808. Milicias de Campeche. Copiador de la correspondencia del gobernador y capitán general Pérez Valdelomar con el teniente de rey y jefes militares de esa plaza. Mérida, 25 de enero y 17 de febrero. AGEY. Colonial, Correspondencia de los gobernadores, 1, 3. Fs. 21-24.

29 Correspondencia de la Contaduría y Tesorería de la Comisaría General del Estado de Yucatán, con diversos jefes militares, del 4 al 30 de julio de 1833. AGEY. Poder Ejecutivo, Milicia, 7, 4. 
JORGE VICTORIA OJEDA

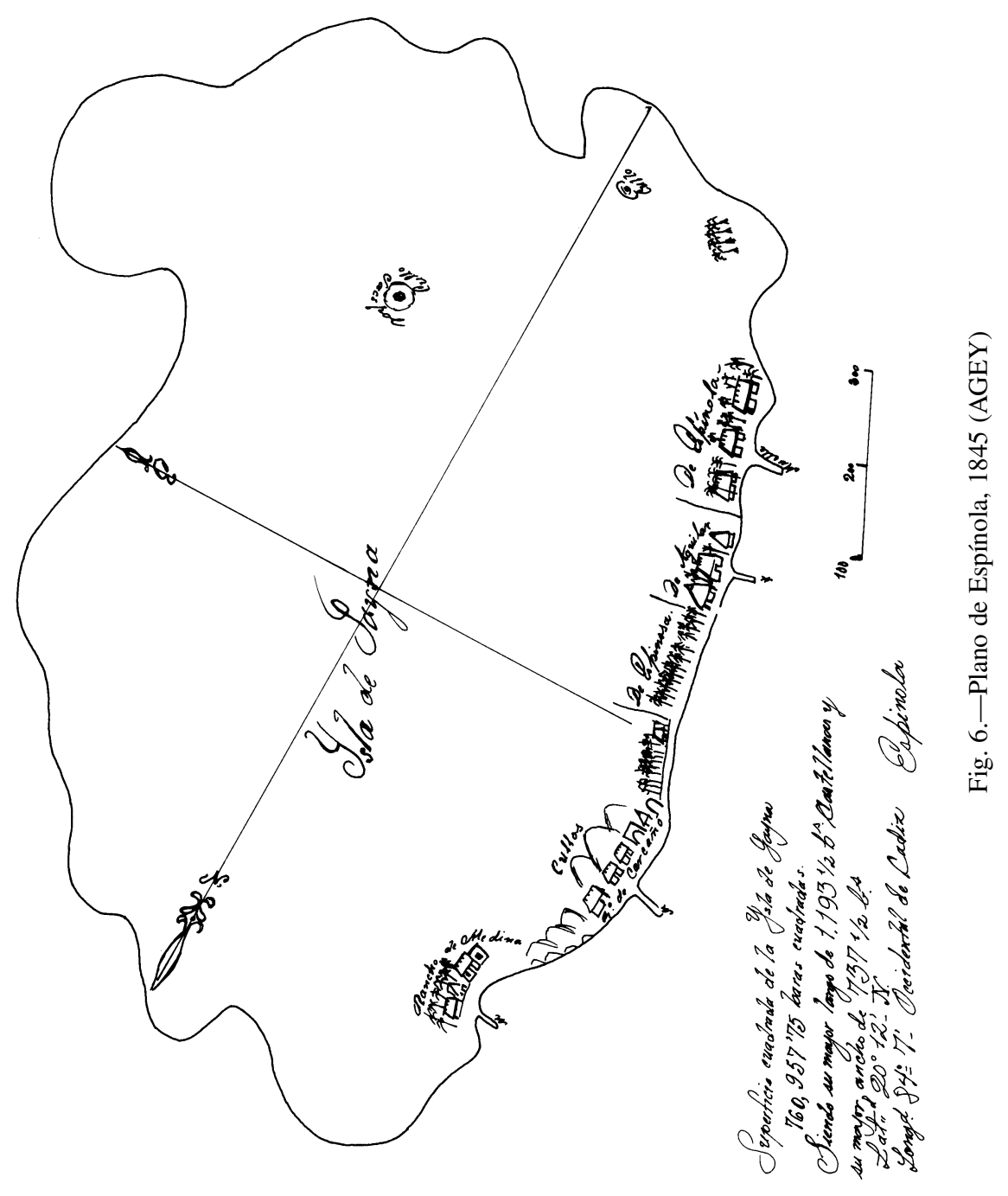


Benavides considera improbable la existencia de esa estructura militar en las cercanías a la isla -en contraposición a lo señalado por Antochiw-, indicando que, en su opinión, el dibujante anónimo tal vez se dejó llevar por las formas de las estructuras prehispánicas del complejo Zayosal, que en cierta manera recuerda la especie de baluarte señalado en el plano (fig. 2). Asimismo indica que, por la desigualdad plasmada en el plano anónimo y en el levantamiento reciente de la isla, hay que tomar en consideración la probable variación morfológica a causa de las erosiones ocasionadas por el mar a través del tiempo. ${ }^{30}$

Por nuestra parte, en agosto de 1996 el autor de este artículo y otros investigadores intentamos, sin saber de las averiguaciones de Benavides Castillo, corroborar los datos del plano citado, para lo cual se recorrió parte de la costa cercana a la isla y se realizaron diversas entrevistas entre la población que vive en el pueblo de Pomuch y en la hacienda Sodzil para indagar respecto a la probable existencia de alguna estructura colonial en la costa o cercana a ella; en ambos casos los resultados fueron negativos, llegando por consiguiente a la consideración de lo apócrifo del plano del puesto militar de Jaina.

Es difícil que los muros y la "batería de campaña" se hayan pensado realizar en la isla por lo lejano de alguna población, lo que imposibilitaría el envío de ayuda en caso necesario. Es más factible que el propio anonimato del autor ayude a pensar que -tal como señala Benavides- sea una inspiración con base en las obras prehispánicas existentes.

Por otro lado, a pesar de que el texto del plano indica que las obras ya habían sido edificadas, no hay que descartar que la manufactura del documento gráfico haya sido con intenciones de engañar a la Corona referente al celo que las autoridades provinciales ponían en la defensa de la península.

\section{Las trincheras del camino a Jaina}

El segundo punto a tratar en este artículo se deriva de las pesquisas realizadas en la región cercana a Jaina, y se refiere a la serie de barricadas que se localizan a la vera del camino que conduce a esa isla.

30 Benavides Castillo, Antonio: comunicación personal. Este arqueólogo recorrió la isla y las costas cercanas en busca de vestigios de las obras militares, en el marco de la elaboración de un proyecto arqueológico a desarrollar en Jaina. Por su parte, Ortiz Lanz, Piedras ante el mar..., pág. 97, indica que la obra militar fue construida con piedras provenientes de las antiguas edificaciones mayas, por lo que concluye que es posible "que subsistan sus restos confundidos con los muros prehispánicos". 
Sobre estas construcciones ya se tenían referencias por comunicaciones personales y posteriormente por una publicación de los arqueólogos Barrera Rubio y Leyba, quienes señalan que las construcciones están dispuestas regularmente en filas, constituyendo una vía fortificada, de manera similar a las reportadas en Ixil, ${ }^{31}$ y otras de la costa del norte peninsular. ${ }^{32}$ Añaden que, aunque no hicieron un estudio detallado de aquellas obras, por sus características y factura ubican el momento constructivo entre los siglos XVII y XVIII, teniendo como finalidad evitar la penetración de los piratas tierra adentro y proteger el camino real que unía Mérida con Campeche..$^{33}$

Por nuestra parte, hemos realizado una investigación de campo y sobre todo documental un tanto más profunda, sin por ello omitir que la región merece un mejor reconocimiento visual y topográfico para tener una comprensión más lúcida. ${ }^{34}$

En el kilómetro 9 del camino rumbo a la costa, después de la hacienda Sodzil, se comienzan a observar una serie de parapetos, localizados a unos 100 metros a la derecha del camino. Se agrupan en número de tres, y sus alturas son de aproximadamente un metro por 1,20 de ancho y algunas de 2,50 metros de largo, y con orientaciones diversas y en alguna ocasión tratando de cubrir una mayor área por su distribución semicircular. Poco más adelante se encuentra otro grupo de dimensiones similares, variando únicamente su longitud ya que este parapeto es de 5 metros de largo (fig. 7).

Avanzando unos 300 metros más hacia la costa comienzan otras estructuras, llegando a contabilizarse más de 40 parapetos de variadas dimensiones, ubicación y forma en aproximadamente un kilómetro cuadrado. ${ }^{35}$

La factura de estas trincheras coincide con las llamadas "de piedra suelta" reportadas en Yucatán desde los inicios de la colonia, teniendo pruebas materiales de otras similares para el siglo XVIII y de parapetos con tales rasgos para la guerra de castas (1847-1901). Por lo tanto, su condición de obras pétreas sin aglutinante no puede ser considerada como rasgo de datación, ni tampoco es válido señalar dos siglos de tentativa temporalidad

31 Barrera Rubio, Alfredo, y Miguel Leyba: "Las trincheras: un sistema colonial de defensa de la costa norte de Yucatán”, Cuadernos de Arquitectura Virreinal, n. ${ }^{\circ}$ 14, México, 1994, pág. 53.

32 Al caso, consúltese Victoria Ojeda, Jorge: Mérida de Yucatán de las Indias. Piratería y estrategia defensiva, México, 1995, págs. 105-126.

33 Barrera Rubio y Leyba: "Las trincheras...”, pág. 53.

34 El recorrido de campo se realizó en compañía de los historiadores Jorge Canto Alcocer, Esteban Poot Quintal y Carlos Pérez y Pérez.

35 Cabe señalar que en aquellos meses se estaba reparando el camino a Jaina y los trabajadores provenientes de la hacienda Chuncaná tomaban parte de las piedras de esos parapetos para romper y utilizar en el relleno. 
ARQUITECTURA MILITAR EN LA REGIÓN DE JAINA, CAMPECHE, MÉXICO

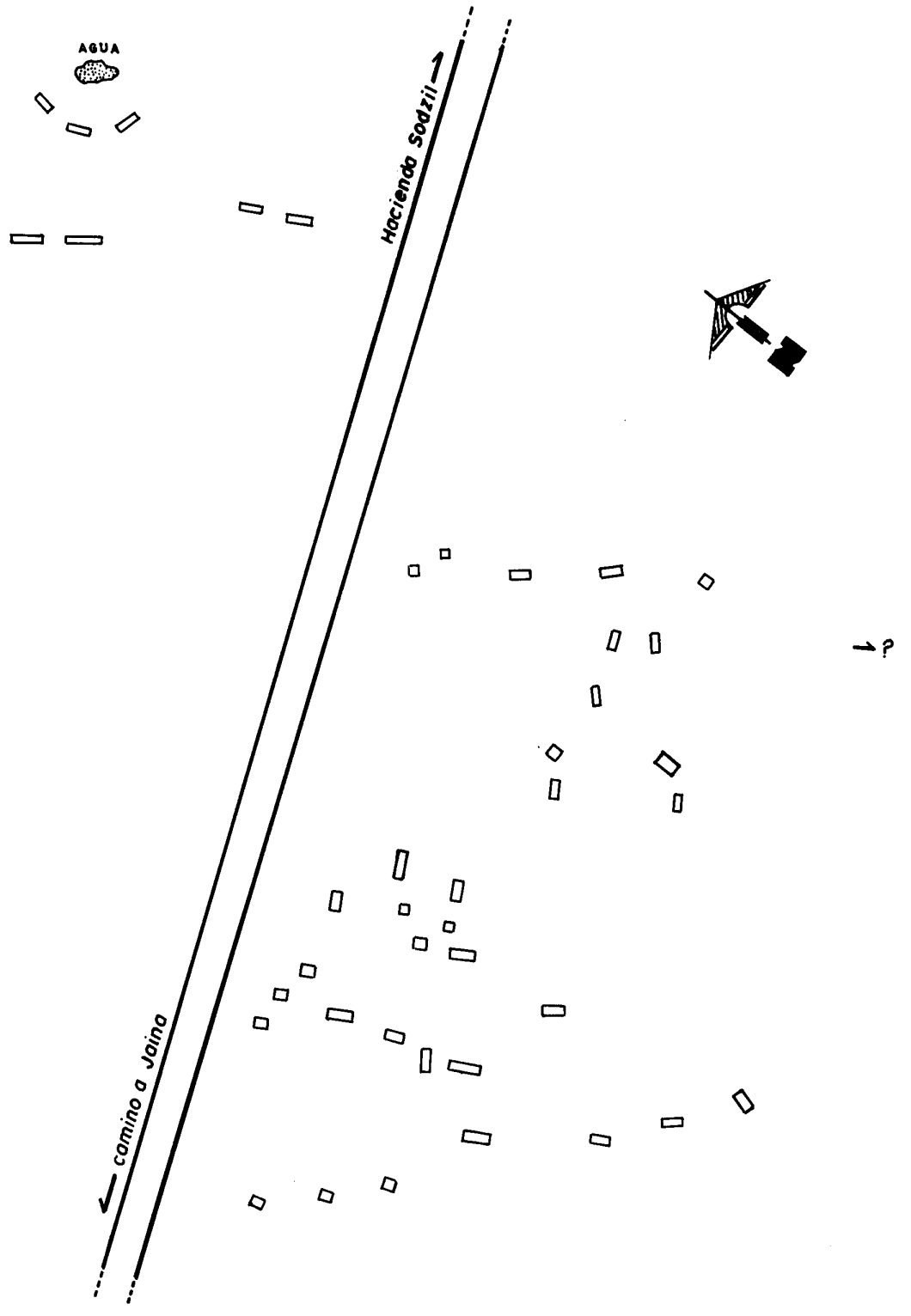

Fig. 7.-Croquis de los parapetos del camino a Jaina, Campeche 
constructiva, tal como apuntan Barrera y Leyba. En cuanto a sus características tácticas como defensas a la vera del camino, al igual que las llamadas trincheras de los accesos a Mérida, son concordantes, pues era de esperar que el enemigo llegase por esa vía. Pero, si por características se entiende su conformación morfológica y distribución espacial, éstas no son similares a aquéllas como señalan los mentados arqueólogos.

Otro punto de interés es la existencia de parapetos pequeños de un metro de altura por un metro de ancho, y a discordancia de las trincheras de piedra suelta de Ixil, ninguno de los muros presenta piedras verticales que hagan las veces de troneras. Para el entendimiento de las diversas formas que presentan estas obras hay que considerar los tipos de armas y su utilización tanto por los invasores como por los defensores, no sólo en cuanto a fusiles sino también de cañones.

A las barricadas o trincheras del camino a Jaina se les ha atribuido una temporalidad constructiva bastante amplia, sobre todo si consideramos que el llamado "período colonial" en México duró 300 años. Por nuestra parte nos abocamos a estudiar la región desde tiempos coloniales, la cual aparece como despoblada y descuidada por las autoridades españolas o novohispanas, debido quizás a las características del litoral norte de Campeche donde los manglares y la escasez de playa son dominantes. En todo ese lapso no se consideró motivo u opción que justificase la construcción de los parapetos, sino hasta la primera mitad del siglo XIX, proponiendo como temporalidad constructiva el lapso de 1828 a 1843.

\section{Hipótesis en cuanto a la datación de las trincheras del camino a Jaina}

Por el abandono que presentó la región en el rubro de la custodia hasta 1833 parece poco probable el levantamiento de los parapetos, situados tierra adentro, en tiempos en que no se contaba con algún punto costero que mandase los avisos consecuentes para el envío de tropas. Sin embargo, el inicio de la temporalidad propuesta se basa en los mandatos emitidos en cuanto al cierre de caminos a la costa para evitar una probable invasión. La fecha terminal de la temporalidad propuesta se debe a que después de la agresión a Yucatán procedente del centro de México, efectuada en 1843, no se halló en la documentación posterior a ese año elementos significativos de probable invasión que justifiquen la construcción. 
Hipótesis A: En los años de 1828 y 1829 se vivió en la península una situación de temor ante la probable invasión española desde Cuba, en sus intentos de reconquista. ${ }^{36}$ En prevención de ello las autoridades yucatecas mandaron cerrar u obstaculizar los caminos de la costa. ${ }^{37}$ Para esos años, en Jaina debieron de persistir algunos ranchos pesqueros que fueron señalados por Molas en 1817 y que posteriormente indicaba Espínola en 1845. La consideración de la isla como único punto de posible desembarque en toda la costa norte de Campeche pudo influir para la construcción de los parapetos.

Hipótesis B: En 1838, debido al conflicto de México con Francia, se ordenó el reforzamiento de la seguridad de la costa peninsular. Así, el 8 de noviembre de ese año Basilio Ramírez, prefecto del distrito de Mérida, señalaba al gobernador lo siguiente:

"He repetido sus órdenes para que en las vigías y pueblos fronterizos se tenga el mayor cuidado y vigilancia, dando avisos continuos, así los jueces de paz como los vigías de cuanto buque se aviste, sus maniobras y demás que ocurran para evitar toda sorpresa. Tengo la satisfacción de participar a Vuestra Excelencia que se hayan ya obstruidos todos los caminos, del mismo modo que fueron cerrados en los años de 1828 y 1829, a cuya operación violenta concurrieron muy gustosos todos los pueblos inmediatos a la costa". ${ }^{38}$

La vigía instalada en Jaina en 1833 pudo complementar la seguridad de esa parte del litoral en el caso de 1828-29, o bien ser una especie de parteaguas, en el caso de que las obras en cuestión se hayan realizado en 1838.

Hipótesis $C$ : Ésta es tal vez la más sustentable y cierra el corto lapso que proponemos para la erección de los parapetos del camino a Jaina. En tal caso, la información recopilada indica que en marzo de 1843 se realizó una expedición mexicana hacia tierras yucatecas con la intención de invadirlas, integrada por tres vapores, dos bergantines y dos goletas, aunque otros documentos acusan que la flota se componía de once o doce naves, y el total de doce mil militares. ${ }^{39}$

36 Al caso, ver Sosa Rodríguez: Proyectos de invasión..., y Victoria Ojeda: "Planes de reconquista del Yucatán independiente: el proyecto de Manuel de Mediavilla", Revista Complutense de Historia de América, n. ${ }^{\circ}$ 22, Madrid, 1996, págs. 275-285.

37 Correspondencia del prefecto del distrito de Mérida con el gobernador del departamento. Del 30 de enero al 26 de noviembre de 1838. AGEY. Poder Ejecutivo, Correspondencia Oficial, 8, 1.

38 Ibídem.

39 AGEY. Poder Ejecutivo, Gobernación, Secretaría de Guerra y Marina, Comandancias, Año 1843, Lugar Varios, Caja 52. 
De esas tropas, 600 u 800 milicianos desembarcaron en Celestún, al norte de Jaina, teniendo avanzadas hacia diferentes lados de la costa. Ante tales noticias, en el puerto de Sisal se tomó la precaución de reforzar las armas del reducto de Santiago y construir merlones a la batería baja existente. Mientras tanto, en la ciudad de Campeche se había erigido una trinchera en el barrio de San Román, pensando en el acoso por Lerma, tal como sucedió. Poco después del mes de septiembre se corría la noticia de que 300 hombres habían desembarcado en Telchac, al noreste de Mérida, y en las cercanías del propio Sisal, sito al noroeste, con intenciones de tomarlo por la retaguardia. ${ }^{40}$

Entre toda esa problemática, que giraba en torno a la región de Campeche hasta Telchac, teniendo como punto álgido Sisal, se informaba a don José de Cárdenas, secretario de marina, que el 17 de marzo de 1843 hallábanse fondeados frente a la isla de Jaina la mayor parte de los buques enemigos. ${ }^{41}$ El gobierno yucateco, previniendo algún intento de invasión por el único punto posible de aquella costa para adentrarse a tierra, tomar el camino real y atacar por la retaguardia a la ciudad capital, pudo mandar erigir las trincheras en cuestión. Ante el acoso a la península, las autoridades respondían de manera determinante en la costrucción de obstáculos y medidas de defensa menores, como son los parapetos. El caso propuesto no sería aislado, ya que se ha señalado cómo se mandaba cerrar caminos, y más tempranamente, el ejemplo de 1807, cuando el entonces gobernador Benito Pérez Valdelomar ordenó al capitán y comandante de artillería, Juan Nepomuceno Rivas, pasar a la Subdelegación de Hunucmá para "cortar y fortificar el paso de la ciénaga para frustrar y dificultar a los enemigos cualquier intento de desembarco". ${ }^{42}$

A pesar de presentar tres temporalidades potenciales, consideramos con mayor peso la idea de que esas obras defensivas de la vía a la isla de Jaina provienen de esta última. Recordemos que José Gora, quien vivió en Yucatán 50 años, en su plan de invasión a la provincia realizado entre 1828 y 1829 , proponía como uno de los puntos de inicio de ese movimiento la isla de Jaina, por lo cual debió considerar que el camino estaba libre de obstáculos o, en su defecto, hacer el pertinente señalamiento de la existencia de alguno que, como en el caso de la obra militar de Jaina, pudiese servir a los invasores como bastión después de tomarlo.

40 Ibídem.

41 Ibídem.

42 Subdelegaciones. Copiador de la correspondencia del gobernador Benito Pérez Valdelomar con los subdelegados y jueces españoles. Mérida, 17 de enero de 1807. AGEY. Colonial, Correspondencia de los gobernadores, $1,2$. 
La ubicación de las obras un tanto lejanas de la costa pudo deberse a la consideración de que ambos bandos utilizarían y tendrían que remolcar cañones. Si la espera fuese en los dos kilómetros antes de la costa donde se reporta suelo firme, o en la propia isla, podría presentarse el problema del abastecimiento, lo cual no ocurriría si se situaban las tropas tierra adentro, más cercanos al camino real.

A la par de la participación de las autoridades en la construcción de los parapetos, no hay que perder de vista la intervención de los particulares en la defensa del territorio a través de la historia, ${ }^{43} \mathrm{y}$ en el presente caso tenemos que la hacienda Sodzil, a escasos kilómetros del inicio de los parapetos, era, en las primeras décadas del siglo XIX, una de las propiedades más valiosas de la región campechana ${ }^{44}$ por lo cual el propietario pudo tener participación en el levantamiento de aquellas trincheras intentando la salvaguarda de sus intereses.

\section{Consideraciones finales}

En base a lo antes señalado se ha pretendido apuntar y corregir dos datos falsos de la historia defensiva de la península de Yucatán. Como se ha señalado, la inclusión de la defensa de Jaina y de las barricadas para tiempos coloniales obligaba a reconsiderar la estrategia y el emplazamiento militar no sólo en aquella región, sino en toda la antigua provincia. A pesar de que se ha hablado de piratas y fabulosas leyendas de corsarios en torno a la isla, originadas en relatos de viajeros ${ }^{45}$ lo cierto es que Jaina permaneció prácticamente abandonada hasta finales del siglo XVIII. A partir de esa centuria no se descarta la práctica del comercio ilícito entre sus moradores y algunos navegantes, pero sin duda no corresponden a la descripción de los temibles personajes de siglos anteriores.

43 Victoria Ojeda: Mérida de Yucatán..., págs. 65-70.

44 Millet Camara, Luis: Mirador Campechano, Campeche, 1994, pág. 80.

45 En sus relatos el filibustero inglés William Dampier (1652-1715), apuntaba que para el siglo XVII la isla era ocasionalmente utilizada por los piratas, realizando la observación de la mar desde uno de los cerros existentes: Dampier's Voyages, E.P. Dutton, tomo 1, New York, 1906, págs. 146, 470. Héctor Pérez Martínez: Piraterías en Campeche Siglos XVI, XVII y XVIII, México, 1937, pág. 62, apunta que en 1692 un pirata desembarcó con su gente y permaneció diecinueve días en la isla, en espera de atacar Campeche. Estas citas han sido utilizadas por otros autores, a nuestro juicio de manera exagera$\mathrm{da}$, en sus intentos de señalar la isla como refugio de piratas durante buena parte de la época colonial. Por ejemplo, Sotelo Regil, Luis: Campeche en la Historia, México, 1963-1964, I, pág.101; Piña Chan: Campeche durante el período colonial, México, 1977, pág. 78. 